\title{
Strength of a feldspar ceramic according to the thickness and polymerization mode of the resin cement coating
}

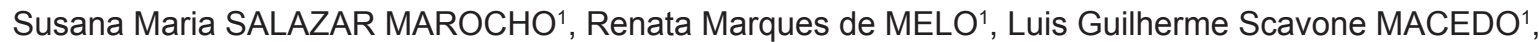 \\ Luiz Felipe VALANDRO ${ }^{2}$ and Marco Antonio BOTTINO ${ }^{1}$
}

\author{
${ }^{1}$ Prosthesis and Dental Materials Department, Sao Paulo State University-UNESP, Av. Engenheiro Francisco Jose Longo 777,12245-820, Sao Jose \\ dos Campos, Sao Paulo, Brazil \\ ${ }^{2}$ Dental School; Department of Restorative Dentistry, Rua Marechal Floriano, 1184, 97015-372, Santa Maria, SP, Brazil \\ Corresponding author, Renata Marques de MELO; E-mail: marquesdemelo@gmail.com
}

\begin{abstract}
The aim of this study was to evaluate, in vitro, the biaxial flexural strength (ISO 6872) of a feldspathic ceramic (VM7, Vita Zahnfabrik) coated with a resin cement with different thicknesses and polymerization mode. Control groups consisted in VM7 with and without acid etching with $10 \%$ hydrofluoric acid for $1 \mathrm{~min}$. Experimental groups comprised VM7 etched, silanated and coated with Variolink II (Ivoclar Vivadent) cement, that was polymerized through the porcelain in light-cure and dual-cure modes, with thickness $\leq 150 \mu \mathrm{m}$ or $>150 \mu \mathrm{m}$. The specimens $(n=15)$ were subjected to the biaxial flexural strength essay and analyzed fractographically. Parametric (Dunnet, Anova 2-way, Tukey) and non-parametric tests (Weibull) were used to evaluate results. Ceramic disks coated with resin cements of either activation modes and thicknesses exhibited higher flexural strength while the Weibull moduli did not present significant differences for a confidence interval of $95 \%$.
\end{abstract}

Keywords: Dental porcelain, Resin cement, Flexural strength, Weibull modulus

\section{INTRODUCTION}

A good adhesive bond of tooth, ceramic and resin cement is essential for the longevity of veneer restorations ${ }^{1)}$. As the fracture of dental ceramics has been associated to oclusal functional loads, static and fatigue studies on the role of the support material in resisting fracture, mainly the penetration of the cement ${ }^{2}$, the cement layer thickness and elastic modulus ${ }^{2,4,5)}$ have arisen.

The ceramic surface modification, to improve interaction with cements was first proposed by Horn ${ }^{6}$, who suggested the use of hydrofluoric acid (HF) on ceramic veneers. Later, Bertolotti ${ }^{7)}$ et al. showed that the acid etching in glass ceramics could create a rough surface, similar to that on the tooth enamel. In low concentration, the hydrofluoric acid dissolves mainly the crystalline phase, whereas in higher concentrations it increases the etched surface area by removing the silica glassy phase. Thus, extending the existing flaws and exposing others on the ceramic surface, the acid etching with HF diminishes the ceramic strength but increases the strength of cemented specimens ${ }^{2}$.

The idea of a hybrid ceramic-composite layer as the strengthening mechanism exerted by resin coatings on veneering porcelains was recently introduced by Addison et $a l^{4)}$. According to the authors the defects created by the roughened surfaces are penetrated by the resin, creating a region sensitive to the elastic modulus of the resin. This has been the most accepted rationale to explain the strengthening mechanism exerted by resin cements, rather than the previously reinforcement hypothesis that the cracks are healed by the cement ${ }^{8)}$ or that stress contraction leads to crack closure ${ }^{9}$. In general, higher elastic moduli are associated with light-polymerization ${ }^{10)}$.
Besides oclusal stresses, thermal variation and saliva ${ }^{11}$, moisture from dentin may also affect the ceramic-cement interface. The water absorption causes the expansion of the polymer matrix, decreasing the strength and the elastic modulus of the cement. When water reaches the cemented surface, ceramic crowns may be distorted, resulting in stresses that favor the subcritical crack growth and fracture ${ }^{5)}$.

The thickness of the cement also has the potential to change the restoration performance under static loading or fatigue. Very thin layers of cement caused an apparent increase of elastic modulus ${ }^{12,13)}$.

Ceramic strength data is generally not normally distributed about the mean because it depends mainly on the flaws distribution inside the material. More general distributions, such as the Weibull 2-parameter distribution give a better description of the strength variability. The two parameter estimates are the Weibull modulus $(m)$ and the Weibull characteristic strength $\left(\sigma_{0}\right)$ that respectively represent the material reliability (based on the strength data distribution) and the stress responsible for $63.21 \%$ of the sample failures ${ }^{14,15)}$.

It is not yet known how ceramic-cement specimens of varying cement thickness and polymerization mode behave in water. To answer this question we assessed the biaxial flexural strength $(\sigma)$ and Weibull associated parameters ( $m$ and $\sigma_{0}$ ) of coated and non-coated porcelain specimens. Fractographic analysis of the specimens fractured under static loading was also performed.

\section{MATERIALS AND METHODS}

Specimen preparation

Ninety disk-shaped specimens were made out of a micro- 
particulate feldspathic ceramic (Vita VM7, VITA Zahnfabrik, Bad Säckingen, Germany) and subjected to the biaxial flexural test, in wet environment, based on the guidelines of ISO $6872^{16)}$ (Fig. 1). The materials used in the study are listed in Table 1.

The ceramic powder and the modeling liquid (Vita Modeling fluid, Vita) were mixed and inserted under vibration in a metallic matrix $12 \%$ larger than the final

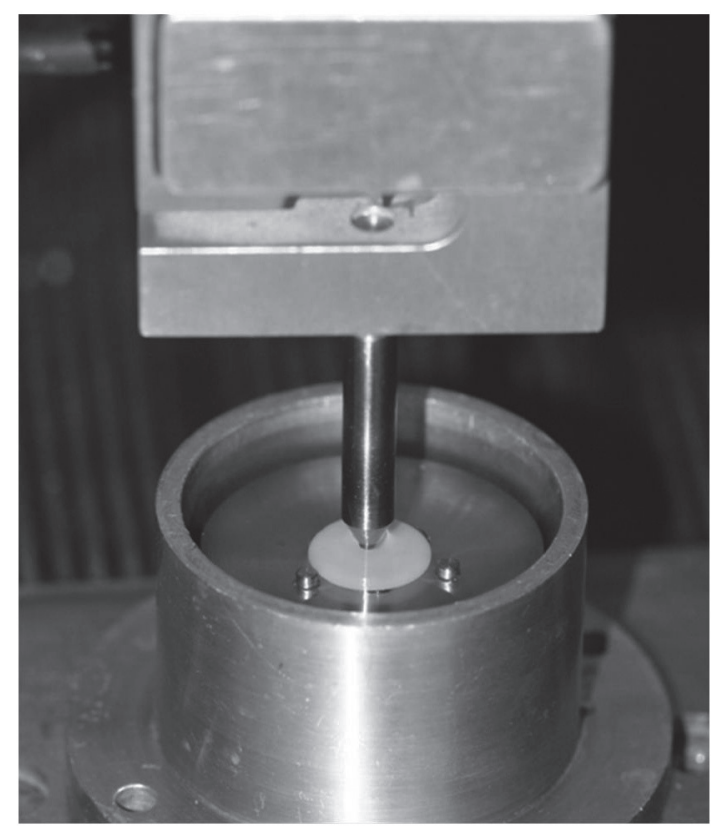

Fig. 1 Biaxial flexural strength test set-up and specimen. specimen to compensate the ceramic contraction. The powder was condensed and the excess of liquid was removed with absorbent paper. The disks were sintered to a firing cycle (Table 2) according to the manufacturers' instructions in a vacuum furnace (Vita Vacumat 40, Vita).

After being air cooled, the disks were flattened with $\mathrm{SiC} \# 120,400,600,800$ and 1200, under coolant irrigation, at $300 \mathrm{rpm}$. Thirty disks were assigned to the control groups. Half were conditioned with Hydrofluoric acid (10\% Hydrofluoric acid, Angelus, Londrina, Parana, Brazil) for $1 \mathrm{~min}$ (V7 $7_{\mathrm{HF}}$, negative control) and rinsed with tap water, and the other half received no treatment (V7, positive control). The remaining groups were treated as $\mathrm{V} 7_{\mathrm{HF}}$, silanated with Monobond S, allowed to dry for $20 \mathrm{~s}$ and coated with Variolink II (VL) in light cure (L) or dual cure (D) mode. The thickness of the cement layer was controlled through a digital micrometer (Series 369, Mitutoyo America Corporation, Aurora, Illinois, USA) having two parallel plates.

Firstly, the specimen and a mylar sheet were compressed between the plates and the micrometer was zeroed at this position. The plates were then separated, the cement was put on the specimen surface, covered with the strip and the set was compressed again until the micrometer marked $50 \mu \mathrm{m}$ or $100 \mu \mathrm{m}$, resulting in cement layers of $\leq 150 \mu \mathrm{m}(70-150 \mu \mathrm{m})$, and $>150 \mu \mathrm{m}$ $(170-250 \mu \mathrm{m})$ respectively. These thicknesses were chosen because an in vivo study showed that the cement thickness of ceramic crowns is around $150 \mu \mathrm{m}$, depending on the crown region ${ }^{17)}$. The experimental groups formed were $\mathrm{V} 7_{\mathrm{HF}} / \mathrm{VL}_{\leq 150 \mathrm{~L}}, \mathrm{~V} 7_{\mathrm{HF}} / \mathrm{VL}_{\leq 150 \mathrm{D}}, \mathrm{V} 7_{\mathrm{HF}} / \mathrm{VL}_{>150 \mathrm{~L}}$, and $\mathrm{V} 7 \mathrm{HF} /$ $\mathrm{VL}_{>150 \mathrm{D}}$. The specimens' final dimension was approximately $12 \mathrm{~mm}$ diameter and $1.2 \mathrm{~mm}$ thickness.

Table 1 Commercial names, manufacturer, composition and batch numbers of the materials used in the study

\begin{tabular}{|c|c|c|c|}
\hline Material & Manufacturer & Average Composition & Batch \# \\
\hline Vita VM7 (1M2 shade) & $\begin{array}{l}\text { VITA Zahnfabrik, } \\
\text { Bad Säckingen, Germany }\end{array}$ & Micro-particle feldspathic ceramic & 11616 \\
\hline $\begin{array}{l}\text { Variolink II (Yellow/Universal } \\
\text { shade, High viscosity) }\end{array}$ & $\begin{array}{l}\text { Ivoclar Vivadent, Schaan, } \\
\text { Liechtenstein }\end{array}$ & $\begin{array}{l}\text { Bis-GMA, } \\
\text { Triethyleneglycol dimethacrylate } \\
\text { Urethane dimethacrylate, } \\
\text { Benzoylperoxide, } \\
\text { inorganic fillers, ytterbiumtrifluoride, } \\
\text { initiators, stabilizers and pigments }\end{array}$ & $\begin{array}{l}\text { Base } \\
46354 \\
\text { Catalyst } \\
3628\end{array}$ \\
\hline Monobond S & $\begin{array}{l}\text { Ivoclar Vivadent, Schaan, } \\
\text { Liechtenstein }\end{array}$ & $\begin{array}{l}\text { Alcohol solution of silane methacrylate, } \\
\text { phosphoric acid methacrylate } \\
\text { and sulphide methacrylate }\end{array}$ & M63563 \\
\hline
\end{tabular}

Table 2 Firing cycle of Vita VM7 according to the manufacturer's recommendation

\begin{tabular}{|c|c|c|c|c|c|c|c|}
\hline Material & $\begin{array}{l}\text { Pre-drying } \\
\text { temp. }\end{array}$ & $\begin{array}{l}\text { Pre-drying } \\
\text { Time }\end{array}$ & Heating time & $\begin{array}{l}\text { Heating temp. } \\
\text { per min }\end{array}$ & $\begin{array}{l}\text { Initial temp. } \\
\text { under vacuum/ } \\
\text { hold time }\end{array}$ & $\begin{array}{l}\text { Vacuum } \\
\text { time }\end{array}$ & $\begin{array}{l}\text { Final temp. } \\
\text { under } \\
\text { vacuum }\end{array}$ \\
\hline $\begin{array}{l}\text { Vita VM7 } \\
\text { Dentine }\end{array}$ & $500^{\circ} \mathrm{C}$ & $6 \min$ & $7.27 \mathrm{~min}$ & $55^{\circ} \mathrm{C}$ & $910^{\circ} \mathrm{C} / 1 \mathrm{~min}$ & $7.27 \mathrm{~min}$ & $600^{\circ} \mathrm{C}$ \\
\hline
\end{tabular}


For the groups that received the coating of dual-cured resin cement, equal amounts of cement base and catalyst were dispensed and mixed. For all experimental groups, the resin cement was polymerized through the porcelain for $80 \mathrm{~s}\left(750 \mathrm{~mW} / \mathrm{cm}^{2}\right.$, Demetron Optilux 501, SDS Kerr, Danbury, CT, USA). Further polymerization of $20 \mathrm{~s}$ was attained after the specimen was removed from the micrometer to ensure the polymerization of the cement at the center of the disk. The specimens were kept in distilled water at $37^{\circ} \mathrm{C}$ for $24 \mathrm{~h}$ before testing.

\section{Mechanical testing}

The specimens were placed onto three stainless-steel balls with diameter of $3.2 \mathrm{~mm}$, equally spaced along a support circle (ISO 6872 ${ }^{16)}$ ). The device for testing was placed in the universal testing machine (Emic DL-1000, Emic, São José dos Pinhais, PR, Brazil), aligned with respect to the piston to ensure that the loading was symmetrical and concentric (Fig. 1). During the flexural test, the specimens were immersed in distilled water at a constant temperature of $37^{\circ} \mathrm{C}$. The load (50 kgf) was applied at a constant speed $(1 \mathrm{~mm} / \mathrm{min})$ until fracture occurred. The coated surfaces of the experimental groups were put on the tensile side.

Using equations 1-3 according to the guidelines of ISO $6872^{16)}$, the biaxial flexural strength ( $\left.\mathrm{MPa}\right)$ was calculated.

$$
\sigma=0.2387 \mathrm{P}(\mathrm{X}-\mathrm{Y}) / \mathrm{b}^{2}
$$

Whereas $\sigma$ is the maximum tensile stress in Pascal, $P$ is the total load causing fracture in Newton, and $b$ is the specimen thickness at fracture origin in millimeters. $X$ and $Y$ were determined as follows:

$$
\begin{aligned}
& \mathrm{X}=(1+v) \ln \left(\mathrm{r}_{2} / \mathrm{r}_{3}\right)^{2}+[(1 v) / 2]\left(\mathrm{r}_{2} / \mathrm{r}_{3}\right)^{2} \\
& \mathrm{Y}=(1+v)\left[1+\ln \left(\mathrm{r}_{1} / \mathrm{r}_{3}\right)^{2}\right]+(1 v)\left(\mathrm{r}_{1} / \mathrm{r}_{3}\right)^{2}
\end{aligned}
$$

In which, $v$ is Poisson's ratio (use Poisson's ratio $=0.25^{21)}$ ); $\mathrm{r}_{1}$ the radius of support circle, in $\mathrm{mm}, \mathrm{r}_{2}$ the radius of loaded area, in $\mathrm{mm} ; \mathrm{r}_{3}$ is the radius of specimen, in $\mathrm{mm}$; $d$ is the specimen thickness at fracture origin, in $\mathrm{mm}$.

Parametric statistics was used to compare the

Table 3 Groups, number of specimens $(n)$, flexural strength means $(\sigma)$, and statistical parameters $\left(m\right.$ and $\left.\sigma_{0}\right)$ obtained from the Weibull Distribution of the initial mechanical strength. Numbers in parentheses are standard deviations (SD)

\begin{tabular}{lcccc}
\hline Groups & $n$ & $\sigma$ & $m$ & $\sigma_{0}$ \\
\hline $\mathrm{V} 7$ & 15 & $49.7(5.83)$ & $9.2(1.7)$ & $52.4(1.5)$ \\
$\mathrm{V} 7_{\mathrm{HF}}$ & 15 & $47.5(7.12)$ & $8.0(1.6)$ & $50.4(1.7)$ \\
$\mathrm{V} 7_{\mathrm{HF}} / \mathrm{VL}_{\leq 150 \mathrm{D}}$ & 15 & $68.5(11.2)$ & $6.7(1.3)$ & $73.4(2.9)$ \\
$\mathrm{V} 7_{\mathrm{HF}} / \mathrm{VL}_{>150 \mathrm{D}}$ & 15 & $62.0(12.7)$ & $5.8(1.2)$ & $67.0(3.1)$ \\
$\mathrm{V} 7_{\mathrm{HF}} / \mathrm{VL}_{\leq 150 \mathrm{~L}}$ & 15 & $55.6(10.5)$ & $6.8(1.4)$ & $59.6(2.3)$ \\
$\mathrm{V} 7_{\mathrm{HF}} / \mathrm{VL}_{>150 \mathrm{~L}}$ & 15 & $64.6(11.6)$ & $6.2(1.2)$ & $69.5(3.0)$ \\
\hline
\end{tabular}
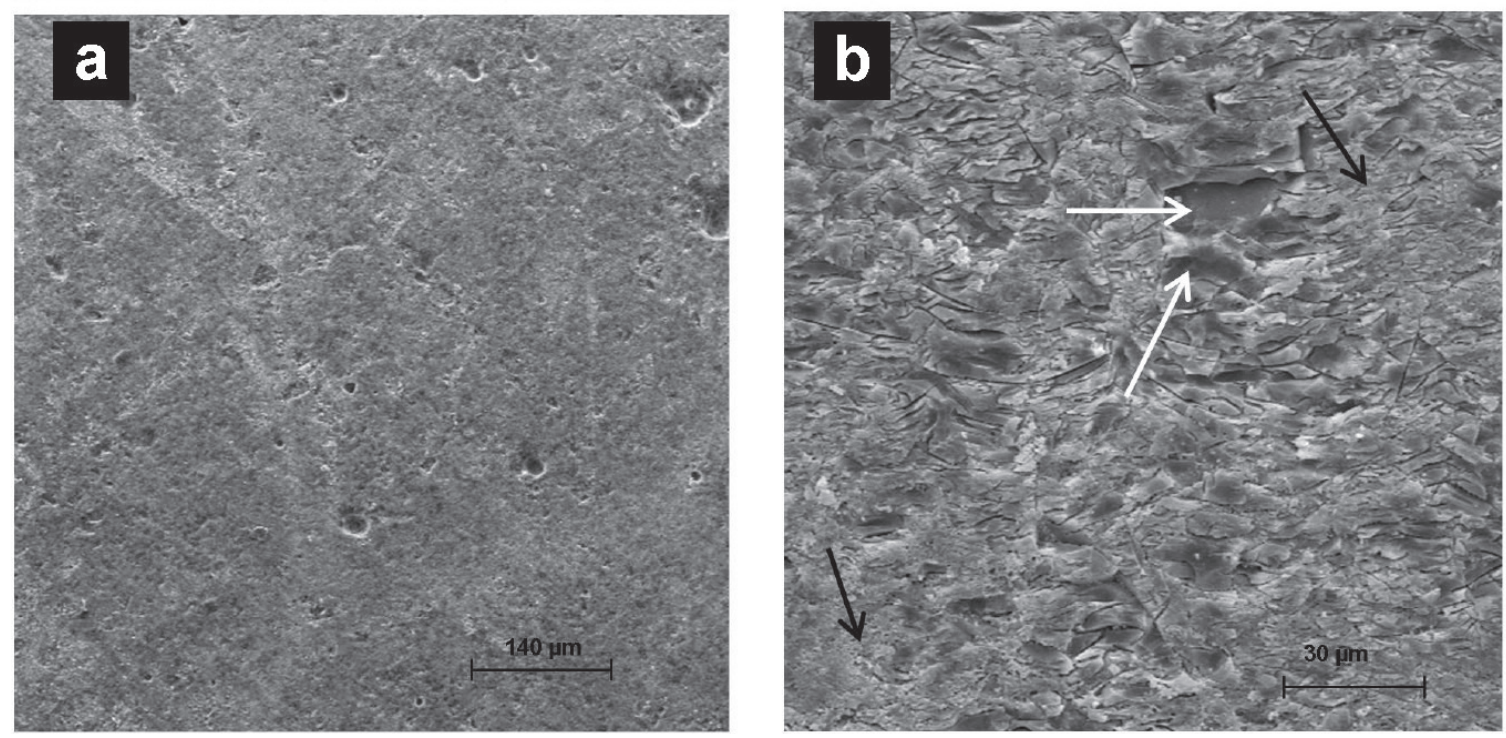

Fig. 2 Topography of V7 (a) and $\mathrm{V}_{\mathrm{HF}}$ (b). The polished surface presents some pores (a). The etched surface in (b) shows rough parts with grooves (white arrows) and insufficiently etched parts with smoother aspect (black arrows). 
biaxial flexural strength mean values. The control group where compared to the experimental ones with Dunnett test $(\mathrm{IC}=95 \%)$. Two-way analysis of variance (ANOVA) and Tukey tests $(p<0.05)$ were conducted for all groups $(n=15)$.

The strength data obtained (initial mechanical strength data) $(\sigma)$ were also analyzed and described using Weibull statistics, using the following equations:

$$
\begin{aligned}
& \ln \ln \frac{1}{1-\mathrm{F}}=m \ln \sigma-m \ln \sigma_{0} \\
& \mathrm{~F}_{\mathrm{x}}=\frac{\mathrm{x}-0.5}{n}
\end{aligned}
$$

where $F_{x}$ is the failure probability of the " $x$ " specimen after ranking the specimens in ascending order according to their strength $(\sigma), n$ is the total number of specimens tested, $\sigma_{0}$ is the characteristic mechanical strength or scale parameter that represents the strength at which $63.21 \%$ of the specimens fail, and $m$ is the Weibull modulus or shape parameter of the distribution of strength data as a function of failure probability. The Weibull parameters, $\sigma_{0}$ and $m$ indicate the magnitude and scattering, respectively, of the measured strength data. The $\sigma_{0}$ and $m$ were calculated from the y-scale intercept and the slope, respectively, of linear fittings to the strength data when plotted in a $\ln \ln (1 /(1-\mathrm{F}))$ versus $\ln (\sigma)$ graph.

\section{Surface and fracture analysis}

The fracture surfaces of the specimens were examined under the combination of optical stereomicroscope (STEMI2000-C; Carl Zeiss, Thornwood, New York, USA) and scanning electron microscope (SEM, JEOL Ltd, Tokyo, Japan) in order to identify the fracture origin and the mode of fracture. For the SEM observations, all specimens were gold-sputtered under vacuum. The fractrographic analysis of several specimens was performed in order to see how the fracture of control and experimental groups differed. Stereoscope examination under various lighting configurations was performed in order to find features that give an indication of the fracture origin. The specimens were then gold sputtercoated for SEM viewing. Additional examination of the specimen surface composition was made through EDS analysis (SEM, JEOL Ltd, Tokyo, Japan).

\section{RESULTS}

The mean values (MPa) and standard deviations are displayed in Table 3. There were no significant differences between the control group means V7 (49.7 MPa) and $\mathrm{V} 7_{\mathrm{HF}}(47.5 \mathrm{MPa})$, whereas the differences between them and the experimental groups were statistically significant (Dunnett test, IC=95\%). The Anova 2-way for the experimental groups revealed that the main factors (polymerization mode $(p=0.08)$ and thickness $(p=0.68)$ did not result in any significant differences, but the interaction factor $(p=0.0097)$ did, showing that $\mathrm{V}_{\mathrm{HF}} \mathrm{VL}_{\leq 150 \mathrm{D}}(68.5 \mathrm{MPa})$ had higher mean strength values than $\mathrm{V}_{\mathrm{HF}} \mathrm{VL}_{\leq 150 \mathrm{~L}}(55.6 \mathrm{MPa})$.

The Weibull statistical parameters $\left(m\right.$ and $\sigma_{0}$ ) are also presented in Table 3. The Weibull modulus ranged from 6.4-13.2 (V7), 5.4-11.8 (V7 $\left.7_{\mathrm{HF}}\right), 4.5-10.2\left(\mathrm{~V} 7_{\mathrm{HF}} /\right.$ $\left.\mathrm{VL}_{\leq 150 \mathrm{~L}}\right), 4.5-9.8\left(\mathrm{~V}_{\mathrm{HF}} / \mathrm{VL}_{\leq 150 \mathrm{D}}\right), 4.2-9.1\left(\mathrm{~V}_{\mathrm{HF}} / \mathrm{VL}>150 \mathrm{~L}\right)$, and 3.8-8.7 ( $\left.7_{\mathrm{HF}} / \mathrm{VL}_{>150 \mathrm{D}}\right)$. The cement coating did not compromise the overall structure of the specimens as no significant differences were observed among the groups, observed by the overlapping of the $95 \%$ confidence intervals of the Weibull modulus $(m)$.

The compositional analysis with EDS showed that the major component elements included Si (25.11\%), Ca (4.79\%), Al (5.5\%), Ba (2.3\%), K (22.1\%) and O (40.2\%). The surface topography of the specimens pertaining to the control groups are showed in Fig. 2.

Stereoscope and SEM images of the fracture surfaces are showed in Fig. 3. For coated and non-coated specimens radial cracks emanating from the cementation surface (tension side) were frequent.

\section{DISCUSSION}

Recently, a study that measured the nano-hardness of the resin luting cement Variolink II polymerized in dual-cure and light-cure modes showed that the elastic modulus of the dual cure $(7.4 \mathrm{GPa})$ material is not so different from the light-cure one $(8.8 \mathrm{GPa})^{5)}$. Based on that, the greatest strengthening would be expected for the light-cure higher modulus groups, but this was not confirmed by the observations in the current study. In fact the mean values of biaxial flexural strength of all cemented groups in the present study revealed a strengthening tendency, whereas the structure reliability was reduced as evidenced by the decrease in the Weibull modulus $(m)$. This reduction was not significant though, as the $95 \%$ Confidence Intervals of the Weibull moduli overlapped.

The weakening effect of the acid etching on V7 was also not significant, not differing from the polished group regarding the flexural strength means and pattern of variability. The percentage of silica in the ceramic composition is high (25.11\%), which makes it very sensitive to the acid reaction ${ }^{14)}$. But, the nature and distribution of flaws on the porcelain surface are dependent on the $\mathrm{HF}$ acid etching time and concentration. While we used $10 \% \mathrm{HF}$ for $60 \mathrm{~s}$, following the manufacturer's instructions, most studies ${ }^{2-4,14)}$ reported using HF 9.5-20\% for $90 \mathrm{~s}$ or above.

Where the defect frequency is low, the least strengthening is observed ${ }^{18)}$. Therefore, less of an etching effect on the ceramic surface may also have had an impact on the Weibull parameters of the fracture stress data of the cement coated groups. The influence of cement thickness and polymerization mode was probably biased by the lack of an efficient cement wetting, decreasing the structure reliability represented by $m$.

The differences between $\mathrm{V} 7_{\mathrm{HF}} \mathrm{VL}_{50 \mathrm{D}}$ and $\mathrm{V} 7_{\mathrm{HF}} \mathrm{VL}_{50 \mathrm{~L}}$ can be understood in terms of level of cure. The degrees 

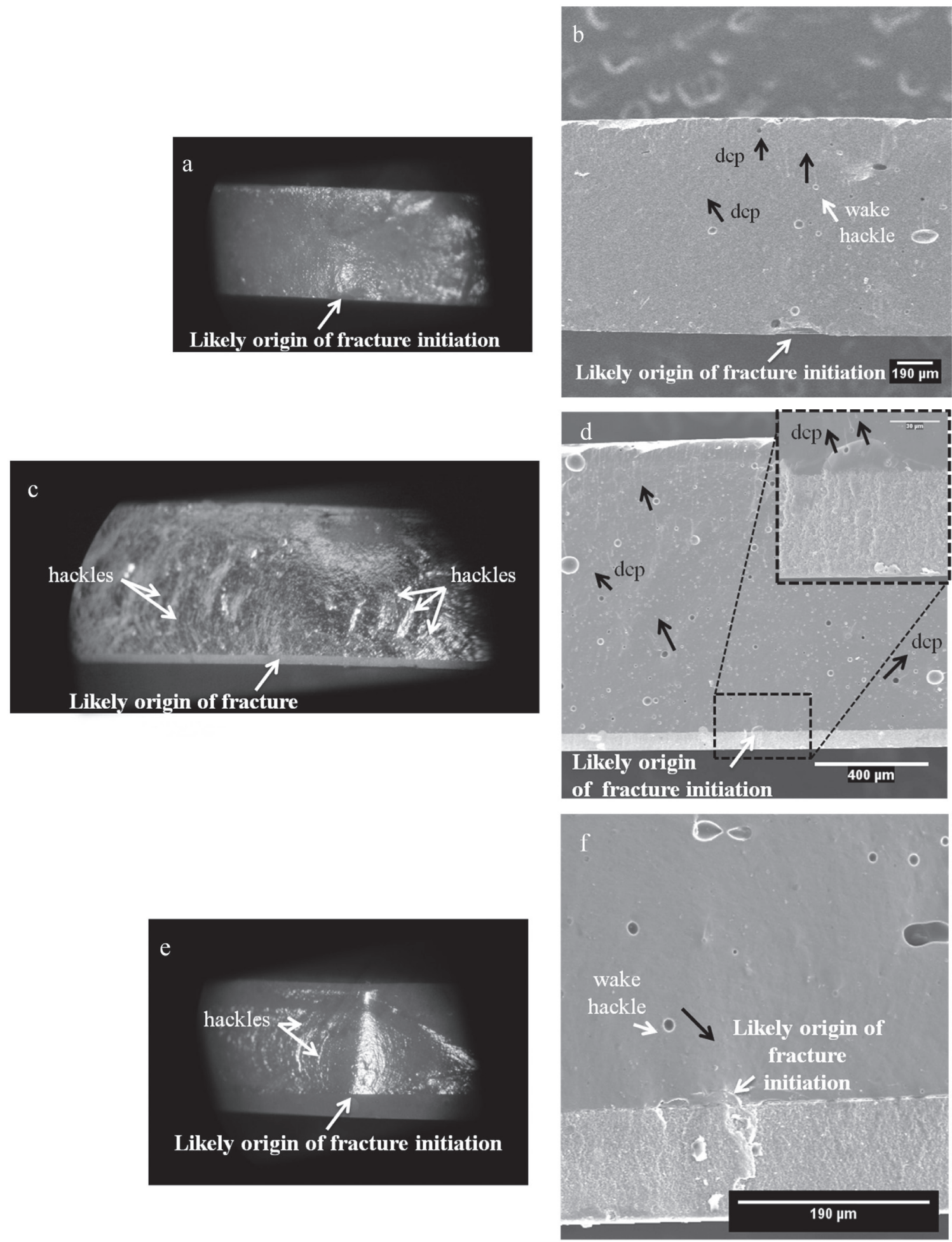

Fig. 3 a-b, c-d, e-f

of conversion of light cure cements is higher than dual-cure ones. That leads to higher volume contraction that probably caused the interfacial gaps seen on the ceramic bottom surface of the light-cured specimens. The presence of discontinuities can harm the bonding quality by exposing the silane hydrolicatically unstable layer. The $\mathrm{V}_{\mathrm{HF}} \mathrm{VL}_{100 \mathrm{~L}}$ specimens also presented gaps, but the higher thickness might have impaired fast water sorption especially at the center area of the specimens. In spite of that, the Weibull data suggested that the flaws 

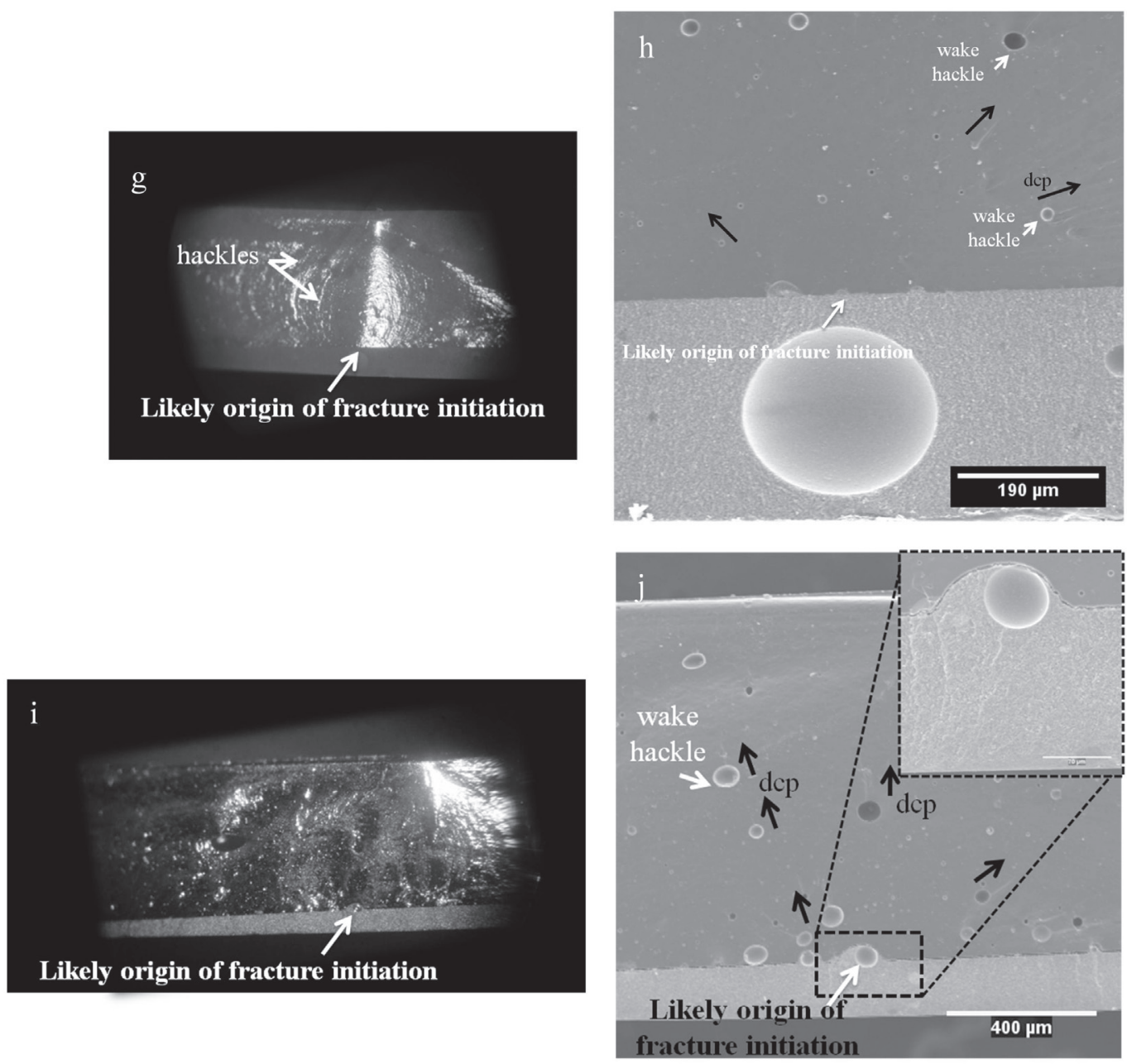

Fig. 3 g-h, i-j

Fig. 3 Fracture surfaces of specimens after the biaxial flexural strength test: a-b $\left(\mathrm{V} 7_{\mathrm{HF}}\right)$; $\mathrm{c}-\mathrm{d}\left(\mathrm{V} 7_{\mathrm{HF}} \mathrm{VL} \leq 150 \mathrm{D}\right)$; e-f $\left(\mathrm{V}_{\mathrm{HF}} \mathrm{VL}_{\leq 150 \mathrm{~L}}\right)$; g-h $\left(\mathrm{V}_{\mathrm{HF}} \mathrm{VL}_{>150 \mathrm{D}}\right)$ and i-j $\left(\mathrm{V}_{\mathrm{HF}} \mathrm{VL}_{>150 \mathrm{~L}}\right)$. a, c, e, g and i are stereoscope images. Side lighting was used to better identify the failure. Hackles are therefore highlighted by a change in shading at the fracture surface. b, d, f, h and $\mathrm{j}$ are SEM secondary electron images. Note several wake hackles are visible starting from pores within the ceramic specimen. Black arrows indicate the direction of crack propagation (dcp) goes from bottom to top. Small squares in Figure $3 \mathrm{~d}$ and $3 \mathrm{j}$ show a detailed view of the site of fracture initiation. $3 \mathrm{c}$ and $3 \mathrm{i}$ show stereoscope analysis of gold-coated fracture surfaces. Tension surfaces are at the bottom.

distributions were not affected by the cement thickness and mode of cure.

Round defects on the ceramic surface coated or not with cement were more likely the points of fracture initiation, located at the tension surface of the specimens $^{5)}$. In all SEM images presented in this study, fracture patterns and fracture surface markings such as hackles ${ }^{19}$ from pores trapped during the ceramic condensation were recognizable, and provide a wealth of clear interpretable information. Mainly, maps of crack propagation direction are constructed, through observations of the wake hackle markings which are considered helpful indicators of the direction of crack propagation $^{20)}$. In the present study, those markings emanated from pores and, based on the former information, were selected as reference for determination of the location of fracture origin in the specimens, as displayed in Fig. 3. Therefore, the fracture process could be explained with respect to the crack's origin and propagation.

For some coated surfaces the fracture features were richer, meaning that greater stresses were necessary to fracture them. The cracks propagated in a radial manner from the ceramic bottom surface to the top and, for the coated specimens, they extended to the cement layer.

We have made comparisons between uncoated and cement coated dental ceramic bi-axial failure stress data using the mono-layered solution established by ISO $6872^{16)}$. Addison and Fleming ${ }^{21)}$ pondered that bi-layered solutions that take into account elastic constants should 
be used instead, especially in specimens having cement thickness higher than $40 \mu \mathrm{m}$. The authors also stated that the symmetry of the distribution for coated specimens is the same when mono-layered or bi-layered solutions are used. Thus, although the ISO solution works well for either coated or uncoated specimens, one limitation of the present study was applying just one solution to compare both types. Further studies with the recommended solutions in concert with fractographic analysis are needed to validate our findings.

\section{CONCLUSIONS}

Within the limitations of the present study, the following conclusions are possible:

1. Etching the ceramic surface for $1 \mathrm{~min}$ did not weaken the ceramic.

2. Water storage for $24 \mathrm{~h}$ may degrade the strength of ceramics coated with light-cured cement layers thinner than $150 \mu \mathrm{m}$.

3. Coating the ceramics in light or dual cure modes, with thicknesses higher or lower than $150 \mu \mathrm{m}$, increased the fracture strength of the ceramic, but did not increase the structure reliability.

4. The fracture of coated and non-coated specimens initiated on round defects on the center of the bottom surface of the ceramics.

\section{ACKNOWLEDGMENTS}

This study was supported by FAPESP (2009/51365-3) and CAPES/CNPq-IEL National- Brazil.

\section{REFERENCES}

1) Guess PC, Stappert CFJ. Midterm results of a 5-year prospective clinical investigation of extended ceramic veneers. Dent Mater 2008; 24: 804-813.

2) Addison O, Marquis PM, Fleming GJ. The impact of hydrofluoric acid surface treatments on the performance of a porcelain laminate restorative material. Dent Mater 2007; 23: 461-468.

3) Addison O, Fleming GJ. The influence of cement lute, thermocycling and surface preparation on the strength of a porcelain laminate veneering material. Dent Mater 2004; 20: 286-292.

4) Addison O, Marquis PM, Fleming GJP. Resin elasticity and the strengthening of all-ceramic restorations. J Dent Res 2007; 86: 519-523.

5) Silva NRFA, Souza GM, Coelho PG, Stappert CFJ, Clark EA, Rekow ED, Thompson VP. Effect of water storage time and composite cement thickness on fatigue of a glass-ceramic trilayer system. J Biomed Mater Res B 2008; 84: 117-123.

6) Horn HR. Porcelain laminate veneers bonded to etched enamel. Dent Clin North Am 1983; 27: 671-684.

7) Bertolotti RL, Lacy AM, Watanabel LG. Adhesive monomers for porcelain repair. Int J Prosthodont 1989; 2: 483-489.

8) Marquis PM. The influence of cements on the mechanical performance of dental ceramics. Bioceram 1992; 5: 317-324.

9) Nathanson D. Principles of porcelain use as an inlay/onlay materials. In: Porcelain and Composite Inlays and Onlays. Gaber GA, Goldstein RE. Chicago: Quintessence; 1993. p. 23-32.

10) Ceballos L, Garrido MA, Fuentes V, Rodriguez J. Mechanical characterization of resin cements used for luting fiber posts by nanoindentation. Dent Mater 2007; 23: 100-105.

11) Huang M, Thompson VP, Rekow ED, Soboyejo WO. Modeling of water absorption induced cracks in resin-based composite supported ceramic layer structures. J Biomed Mater Res B Appl Biomater 2008; 84: 124-130.

12) Sabbagh J, Vreven J, Leloup G. Dynamic and static moduli of elasticity of resin based materials. Dent Mater 2002; 18: 64-71.

13) De Jager N, Pallav P, Feilzer AJ. The apparent increase of the Young's modulus in thin cement layers. Dent Mater 2004: 20: 457-462.

14) Weibull W. A statistical distribution function of wide applicability. J Appl Mech 1951; 18: 293-297.

15) Stewardson DA, Shortall AC, Marquis PM, Lumley PJ. The flexural properties of endodontic post materials. Dent Mater 2010; 26: 730-736.

16) International Organization for Standardization, D.C., 3rd ed.ISO; 2008. ISO 6872 .

17) Ferrari M. Cement thickness and microleakage under Dicor crowns: An in vivo investigation. Int J Prosthodont 1991; 4: 126-131.

18) Addison O, Marquis PM, Fleming GJ. Resin strengthening of dental ceramics - The impact of surface texture and silane. $J$ Dent 2007; 35: 416-424.

19) Quinn JB, Quinn GD, Kelly JR, Scherrer SS. Fractographic analyses of three ceramic whole crown restoration failures. Dent Mater 2005; 21: 920-929.

20) Quinn GD. Guide to practice for fractography of ceramics and glasses, NIST Special Publication SP 960-16, May 2007, Gaithersburg, MD.

21) Addison O, Fleming GJ. Application of analytical stress solutions to bi-axially loaded dental ceramic-dental cement bilayers. Dent Mater 2008; 24: 1336-1342. 